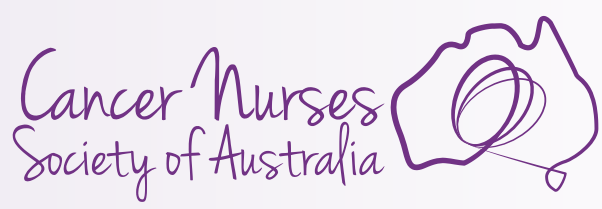

\title{
Editorial: voice, visibility and research
}

\section{Prof Mei Krishnasamy}

Director, Academic Nursing Unit, Peter MacCallum Cancer Centre

Research and Education Lead - Nursing, Victorian Comprehensive Cancer Centre

Sir Peter MacCallum Department of Oncology and Department of Nursing, University of Melbourne, VIC

For referencing Krishnasamy M. Editorial: voice, visibility and research. Australian Journal of Cancer Nursing 2021; $22(2): 1-2$.

DOI https://doi.org/10.33235/ajcn.22.2.1-2

In her powerful book From silence to voice: what nurses know and must communicate to the public, Suzanne Gordon' asks us to consider what would happen if "the voice and visibility of nursing were commensurate with the size and importance of the nursing profession".

The COVID-19 pandemic has given the world insight into our importance and has elevated our visibility. But, even as the pandemic continues to ravage large parts of our globe, governments are already demonstrating a profound case of short-term memory loss about promises made to elevate educational opportunities, salary and a place at the policy table for nurses in response to our contribution during the pandemic ${ }^{2,3}$. Why is this? The reasons are complex, long-standing and engrained, and the magnitude of effort needed to address them are clearly detailed in the WHO's State of the world's nursing, 20204. However, I believe that nurses have access to an underutilised resource, a secret weapon, that, if used effectively, can raise the voice, visibility and importance of nursing - research.

In 2016, the Victorian Comprehensive Cancer Centre (VCCC) was launched. The VCCC is an alliance of 10 organisations, including seven clinical, one university and two research institutes, funded by the Victorian Government (https://www.viccompcancerctr. org). Its mission is to turn the potential of the critical mass and expertise of multidisciplinary clinicians, consumers, researchers and scientists into best possible outcomes for Victorians affected by cancer. One of the flagship programs of the VCCC is the NurseLed Research Hub (the Hub) (https://www.viccompcancerctr. org/what-we-do/research-development/nurse-led-research/). Established to develop cancer nursing research capability, the Hub uses multiple strategies and activities to support nurses to engage in research such as: an online information-sharing forum; free education sessions and workshops; supported research secondment opportunities; training and mentoring; and access to funds for research projects.

In this edition of the Australian Journal of Cancer Nursing, three nurse-led research initiatives are reported. The authors of the profiled papers were recipients of competitively awarded funding provided by the VCCC Hub to carry out clinical research projects. To be eligible for funding, the nurses had to engage nurses from across VCCC alliance organisations, creating opportunity to build or strengthen research networks and collaborations, and maximise visibility of their work. The framework underpinning the intent of the seed funded projects - and the Hub more broadly - is the Institute of Medicine's six quality aims ${ }^{5}$ of safety, effectiveness, patient-centredness, timeliness, efficiency and equity of care.

In the first paper, Diane Davey and colleagues present their work Improving patient preparation for implanted ports: a mixed methods study to establish clinical utility of a novel cancer nursing patient education resource. Driven by evidence of lack of standardisation of nurse-led patient preparation for the insertion of an implanted port, Diane and her colleagues set out to test clinical utility of a novel, co-produced education resource, with nursing colleagues across five hospitals in Melbourne. The paper details the development of the study design, demonstrates appropriateness of mixed methods approaches to nursing practice inquiry, and offers insight to the relevance of a multi-dimensional framework of clinical utility to evaluate nursing interventions. Importantly, the paper demonstrates the potential of her initiative to deliver equitable, effective, patientcentred care.

In the paper The TransAllo study: factors influencing attendance at and experiences of a long-term follow-up clinic postallogeneic bone marrow transplant for patients transitioning from paediatric to adult services, Yvonne-Panek Hudson and colleagues explore both the barriers and the enablers to smooth transition in care for patients at high risk of complex, long-term health impacts. Yvonne and her colleagues had noticed suboptimal first-time attendance of adolescents and young adults to their adult long-term follow-up clinic. Cognisant of the potential health consequences, the team set out to better understand barriers to engagement using an interpretive descriptive approach. Yvonne's paper offers pragmatic recommendations to achieve effective, timely, patient-centred transitional pathways.

In the final paper, Real-world experiences of nurses administering blood transfusions via a central venous access device (CVAD) concurrently with other intravenous (IV) medications for patients with malignant and non-malignant haematological conditions, Andrea Cameron and colleagues document real-world practices and clinical decision-making of in-patient haematology nurses with regard to concurrent administration of multiple IV infusions via CVADs. Using a descriptive, exploratory study design, Andrea 
and her team demonstrated variation in nursing practice within and between organisations when running concurrent and sequential IV medications and blood transfusions. Insights from the study will help inform initiatives to standardise practice, ensuring that care is safe, efficient and effective.

These papers demonstrate the importance of building nursing research capability, providing clinical nurses with the skills necessary to examine, inform and articulate the contribution of our practice at patient, organisation and system levels outcomes. Without evidence to demonstrate the impact of our work, we silence our voice.

In memory of and in gratitude for the passion, excellence and vision of Emma Cohen.

\section{References}

1. Buresh B, Gordon S. From silence to voice: what nurses know and must communicate to the public. London \& Ithaca, NY: Cornell University Press; 2013. p. 13-31.

2. Ford M. Tory MP says nurse pay rise demand 'one for the fairies'. Nursing Times 2021 [cited 2021 Jun 6]. Available from: https://www.nursingtimes. net/news/workforce/tory-mp-says-nurse-pay-rise-demand-onefor-the-fairies-01-03-2021/?eea=OUFqTXhhN3dZVlgvVDEwMmN4 aUpmczR4SDZabkhtU2hRYTJoTGk5Q0xkQT0=\&n_hash=1716\&mkt_ tok=NDA3LUIYQi01MjkAAAF7jg510J35wPUMP_ocvCiSOOOR.

3. Bagnasco A, Catania G, Gallagher A, Morley G. Media representations of nurses in the pandemic: just doing our job? Nursing Ethics 2020 Jun;27(4):901-905.

4. WHO. State of the world's nursing 2020: investing in education, jobs and leadership. Geneva: World Health Organization; 2020.

5. Institute of Medicine (IOM). Crossing the quality chasm: a new health system for the 21st century. Washington DC: National Academy Press; 2001. 